\title{
Risk factors for ductal and lobular breast cancer: results from the nurses' health study
}

\author{
Joanne Kotsopoulos ${ }^{1}$, Wendy Y Chen ${ }^{1,2^{*}}$, Margaret A Gates ${ }^{1,3}$, Shelley S Tworoger ${ }^{1,3}$, Susan E Hankinson ${ }^{1,3}$, \\ Bernard A Rosner ${ }^{1,4}$
}

\begin{abstract}
Introduction: Ductal and lobular carcinomas are the two most common types of invasive breast cancer. Whether well-established risk factors are differentially associated with risk on the basis of histologic subtype is not clear. We prospectively investigated the association between a number of hormonal and nonhormonal exposures and risk defined by histologic subtype among 4,655 ductal and 659 lobular cases of postmenopausal breast cancer from the Nurses' Health Study.

Methods: Multivariate Cox proportional hazards regression stratified by histologic subtype and time period was used to examine the association between risk factors and the incidence of ductal and lobular subtypes. For each exposure, we calculated the $P$ value for heterogeneity using a likelihood ratio test comparing models with separate estimates for the two subtypes versus a single estimate across subtypes.

Results: The associations with age at menarche (P-heterogeneity (het) $=0.03)$, age at first birth $(P$-het $<0.001)$ and postmenopausal hormone use $(P$-het $<0.001)$ were more strongly associated with lobular cancers. The associations with age, nulliparity, parity, age at menopause, type of menopause, alcohol intake, adult body mass index (BMI), BMl at age 18, family history of breast cancer and personal history of benign breast disease did not vary by subtype ( $P$-het $\geq 0.08$ ). Results were similar when we restricted the analyses to estrogen receptor-positive and progesterone receptor-positive tumors.
\end{abstract}

Conclusions: These data indicate that breast cancer is a heterogeneous disease, and the differential association with a number of risk factors is suggestive of etiologically distinct tumors. Epidemiological analyses should continue to take into account a modifying role of histology.

\section{Introduction}

Epidemiologic studies have shown that reproductive, lifestyle and anthropometric exposures are predictive of subsequent breast cancer risk [1,2]; however, whether these factors are differentially associated with risk on the basis of histologic subtype is not clear. Among invasive breast cancer cases, $\sim 75 \%$ are ductal carcinomas, $15 \%$ are of the lobular type and the remainder are a mix of other, less common histologies [3]. Differences in clinical, molecular and pathologic features of ductal and lobular tumors [4] suggest a distinct etiology and may have implications with respect to their prevention,

\footnotetext{
* Correspondence: wychen@partners.org

'Channing Laboratory, Department of Medicine, Brigham and Women's Hospital and Harvard Medical School, 181 Longwood Avenue, 3rd Floor, Boston, MA 02115, USA

Full list of author information is available at the end of the article
}

diagnosis and treatment. Further, lobular cancers are more likely than ductal cancers to be estrogen receptor (ER)-positive and progesterone receptor (PR)-positive $[5,6]$. This might explain why several studies have demonstrated differences in the association between postmenopausal hormone use (PMH) and risk of breast cancer by histology, with a stronger effect seen for lobular carcinomas [7].

Besides the studies of PMH and breast cancer risk by histology, few large studies have evaluated whether the association of other well-established breast cancer risk factors varies by histology [8-10]. Moreover, limitations of prior studies include the lack of formal statistical testing across disease subtypes, small sample size, no control for ER or PR status or the use of retrospective data. Therefore, we prospectively examined the relationship between known breast cancer risk factors and their 
association with the two most common types of invasive breast cancers, ductal and lobular, diagnosed among postmenopausal women from the Nurses' Health Study (NHS) cohort.

\section{Materials and methods Study population}

The NHS was initiated in 1976, when 121,700 female registered nurses between the ages of 30 and 55 and residing in 11 U.S. states completed a self-administered, mailed questionnaire about their medical histories and health-related exposures [11-13]. Every 2 years, followup questionnaires have been mailed to update information on risk factors and disease development. A food frequency questionnaire was added in 1980, and subsequent dietary questionnaires were distributed in 1984, 1986 and every 4 years thereafter. We defined baseline as 1980, the first time we assessed alcohol intake $(n=$ $92,468)$. Follow-up has been high in this cohort $(95.2 \%$ of the total possible person-years through June 2006). The study protocol was approved by the Institutional Review Board at Brigham and Women's Hospital.

\section{Exposure data}

We obtained information on the exposures of interest from one or more of the biennial questionnaires completed by participants. On the baseline questionnaire, we collected information on date of birth, age at menarche, weight at age 18 and current height. The baseline and all subsequent questionnaires requested information on status and duration of $\mathrm{PMH}$ use, menopausal status, type of menopause, history of benign breast disease (BBD) and current weight as well as, beginning in 1978, the type of $\mathrm{PMH}$.

For the other exposures of interest, questions were included on multiple but not all questionnaires, and we updated the value for each covariate when new information was available or otherwise carried forward the value from the previous follow-up cycle. For the exposures that were collected at a single time point (for example, age at menarche), we carried forward the value throughout the remainder of follow-up. Age at menopause was requested on all questionnaires through 2000 and menopausal status was included on all questionnaires through 2002, at which time the youngest participants were 55 years of age. We assessed age at first birth (AFB) and parity on every NHS questionnaire until 1984 and again in 1996 to update the data on each woman's lifetime pregnancy history. Data on family history of breast cancer in a first-degree relative were collected every 4 to 8 years beginning in 1976. Daily alcohol consumption was first queried in 1980, then in 1984 and 1986 and every 4 years thereafter.

\section{Identification of breast cancer cases}

The primary end point was the diagnosis of invasive ductal or invasive lobular breast cancer. Carcinomas in situ were censored. On each questionnaire, we asked whether breast cancer had been diagnosed and, if so, the date of diagnosis. We asked all women who reported breast cancer (or next of kin for those who had died) for written consent to review the pertinent medical records for confirmation. We also searched the National Death Index for breast cancer deaths among women who did not respond to the questionnaires, which accounted for less than $1 \%$ of confirmed breast cancer cases. Pathology reports or cancer registry data were obtained for $95 \%$ of the cases. Histologic type and ER or PR status were based upon extraction from the medical records. Invasive tumors of mixed ductal and lobular type or of other or unknown histology were censored at the date of diagnosis.

\section{Exclusions}

We excluded the following women at baseline from the analysis: those reporting a previous diagnosis of ductal carcinoma in situ (DCIS; $n=26$ ) or any invasive cancer except nonmelanoma skin cancer $(n=4,933)$, those reporting no year of birth $(n=161)$ and those who died before $1980(n=461)$. Women were censored at the time of development of DCIS or any type of invasive cancer except nonmelanoma skin cancer. Only postmenopausal women were included in the analysis, because the analysis included many hormonal factors that may operate differently in pre- and postmenopausal women, and we had limited numbers of woman with premenopausal lobular breast cancers. Women who were premenopausal at baseline began contributing person-time to the analysis at the time that they became postmenopausal. Menopause was defined as natural, radiation-induced (very few women had radiation-induced menopause: $\sim 0.14 \%$ ) or surgical (hysterectomy with or without unilateral or bilateral oophorectomy).

\section{Statistical analysis}

Participants accrued person-time from the return date of the baseline questionnaire until the date of breast cancer diagnosis, diagnosis of any other cancer (excluding nonmelanoma skin cancer), death or the end of follow-up (2006). Participants contributed person-time only for follow-up periods for which they were postmenopausal. For the reproductive and hormonal exposures, we modeled age, age at menarche and age at menopause as continuous variables to minimize the number of parameters in the model. We used categorical variables to model type of menopause (natural or radiationinduced, surgical with two ovaries removed, surgical 
with one or zero ovaries removed and unknown), nulliparous or parous, AFB (AFB <25 years, AFB 25-29 years, AFB 30-34 years, AFB $\geq 35$ years, parity (1, 2, 3, or $\geq 4$ ) and $\mathrm{PMH}$ use (never, past user, current estrogen (E) $<5$ years, current estrogen and progesterone $(E+P)$ $<5$ years, current other $\leq 10$ years, current E 5-10 years or current E+P 5-10 years). For analyses of duration of $\mathrm{PMH}$ use by type of $\mathrm{PMH}$, we included only $\mathrm{PMH}$ use durations of $\leq 10$ years because $\mathrm{PMH}$ use longer than 10 years was for the most part limited to E-alone formulations. $\mathrm{PMH}$ use for women with use for $>10$ years was censored. For the nonreproductive exposures, we modeled recent body mass index (BMI) $(<21,21$ to $<23,23$ to $<25,25$ to $<30$ or $\left.\geq 30 \mathrm{~kg} / \mathrm{m}^{2}\right)$, BMI at age $18(<19$, $19-21,21$ to $<23$ or $\geq 23 \mathrm{~kg} / \mathrm{m}^{2}$ ) and alcohol consumption $(0,<5,5$ to $<15$ or $\geq 15 \mathrm{~g} /$ day) as categorical variables. Continuous variables were used to assess $P$ trend. Family history of breast cancer in a first-degree relative and personal history of $\mathrm{BBD}$ were modeled as binary variables (yes or no). We carried forward the last selfreported exposure data for one cycle if the data were missing. Otherwise, women with missing information were included in the analysis using indicators for the missing variables. Findings were similar in analyses including only nonmissing data (complete case analysis).

We used Cox proportional hazards regression stratified by time period to model the incidence rate ratio (RR) and 95\% confidence interval (CI) of invasive cancer overall for each exposure. We then restricted the analysis to cases with ductal or lobular histology and used Cox proportional hazards regression stratified by type of outcome and time period to allow for different associations by histologic subtype [14]. We used data augmentation, such that each participant had a separate observation for each subtype. We coded the event variable as 1 (failed) if the participant was diagnosed with the histologic subtype corresponding to that data row, and as 0 otherwise; cases were censored for the other subtypes at the time of diagnosis.

We compared a model that assumed different associations for all exposures by histologic subtype (full model) to a model with a single estimate across histologic subtypes for one exposure at a time (reduced model). We calculated the $P$ value for heterogeneity ( $P$-het) using a likelihood ratio test, with the degrees of freedom equal to the difference between the number of parameters in the full and reduced models. Using a stepwise-down approach, we set exposures with a nonsignificant $P$-het $(P>0.05)$ to have a single parameter estimate across subtypes so that the final model estimated two separate associations for exposures that differed significantly by subtype and a single parameter estimate for all other exposures. In the current analysis, we show the results from the model that allowed all the associations to vary (full model). In secondary analyses, we also examined these associations limited to ER-positive and PR-positive tumors.

All analyses were conducted using SAS version 9.1 software (SAS Institute, Cary, NC, USA). All $P$ values were based on two-sided tests and were considered statistically significant if $P \leq 0.05$.

\section{Results}

At baseline, our analysis included 37,127 postmenopausal women and then expanded to 107,759 women by the end of follow-up. During 1,774,075 person-years of follow-up, we observed 6,226 incident cases of invasive breast cancer. Of these, 4,655 were ductal and 659 were lobular carcinomas (see Table 1 for characteristics by case type). The remaining 1,002 were excluded because of no pathology report (8\%), no primary structure evident (1\%), mixed ductal and lobular histologies (4\%) or unknown or other histology (1\%).

\section{Reproductive and hormonal exposures}

There was no heterogeneity in the risk estimates for age, nulliparity, parity, age at menopause or type of menopause by histology $(P$-het $=0.18,0.87,0.35,0.45$ and 0.08 , respectively) (Table 2 ). Although an inverse association with surgical menopause was observed for ductal but not lobular cancers, the $P$-heterogeneity value was not significant.

The associations with age at menarche, AFB and $\mathrm{PMH}$ use differed significantly by histology $(P$-het $=0.03$, $<0.001$ and $<0.001$, respectively). Age at menarche was inversely associated with risk of both ductal and lobular cancers; however, the association was stronger for lobular cancers ( $2 \%$ vs. $8 \%$ decrease in risk for each year increase in age at menarche, respectively).

Increasing AFB was associated with an increasing risk of both ductal and lobular cancers, although the results were stronger for lobular cancers $(P$-het $<0.001)$. For example, compared with the reference group (that is, parous women with an AFB $<25$ ), the RRs associated with an AFB between 30 and 34 years old were 1.21 (95\% CI, 1.09-1.35) and 2.31 (95\% CI, 1.79-2.99) for ductal and lobular cancers, respectively. There was significant heterogeneity when modeling AFB and parity as continuous variables $(P$-het $=<0.001$ and 0.02 , respectively). For ductal and lobular tumors, respectively, the RRs for every 5-year increase in AFB were 1.12 ( $P$ trend $<0.001$ ) and 1.48 ( $P$ trend $<0.001)$, while the RRs for each additional birth were $0.97(P$ trend $=0.01)$ and $1.05(P$ trend $=0.11)$.

There was significant heterogeneity for PMH use across subtypes $(P$-het $<0.001)$. Compared to never users, past use was not significantly associated with risk of ductal or lobular breast cancer $(\mathrm{RR}=1.05 ; 95 \% \mathrm{CI}$, 
Table 1 Baseline characteristics of invasive postmenopausal breast cancer cases and noncases in the Nurses' Health Study in 1980

\begin{tabular}{|c|c|c|c|c|}
\hline & $\begin{array}{c}\text { Noncases } \\
(n=101,533)\end{array}$ & $\begin{array}{l}\text { All invasive cases } \\
(n=6,226)\end{array}$ & $\begin{array}{l}\text { Ductal carcinoma } \\
\quad(n=4,655)\end{array}$ & $\begin{array}{l}\text { Lobular carcinoma } \\
\quad(n=659)\end{array}$ \\
\hline \multicolumn{5}{|l|}{ Reproductive or hormonal characteristics } \\
\hline Mean age $(\mathrm{yr})$ & 53.7 & 54.5 & 54.5 & 54.4 \\
\hline Mean age at menarche (yr) & 12.7 & 12.6 & 12.6 & 12.5 \\
\hline Mean parity among parous women & 3.3 & 3.2 & 3.2 & 3.3 \\
\hline Mean age at menopause $(y r)^{a}$ & 48.7 & 49.5 & 49.4 & 49.7 \\
\hline Ever used postmenopausal hormones (\%) & 47 & 48 & 50 & 51 \\
\hline Natural menopause (\%) & 64 & 67 & 67 & 66 \\
\hline \multicolumn{5}{|l|}{ Nonreproductive characteristics } \\
\hline Mean body mass index $\left(\mathrm{kg} / \mathrm{m}^{2}\right)$ & 24.9 & 25.2 & 25.2 & 24.5 \\
\hline Mean body mass index at age $18\left(\mathrm{~kg} / \mathrm{m}^{2}\right)$ & 21.4 & 21.0 & 21.0 & 21.2 \\
\hline Median alcohol intake (g/day) & 1.8 & 1.8 & 1.8 & 1.8 \\
\hline $\begin{array}{l}\text { Family history of breast cancer in first degree } \\
\text { relative }(\%)^{\mathrm{b}}\end{array}$ & 8 & 13 & 14 & 11 \\
\hline History of benign breast disease (\%) & 22 & 27 & 27 & 30 \\
\hline
\end{tabular}

${ }^{a}$ Among those who experienced natural menopause. ${ }^{b}$ Family history in 1982.

$0.97-1.14$; and $\mathrm{RR}=1.11 ; 95 \% \mathrm{CI}, 0.88-1.39$, respectively). Current use of $\mathrm{E}$ alone for $<5$ years was associated with a statistically significant increase in the risk of lobular cancer ( $\mathrm{RR}=1.56 ; 95 \% \mathrm{CI}, 1.01-2.42)$ but not ductal cancer $(\mathrm{RR}=1.07 ; 95 \% \mathrm{CI}, 0.90-1.28)$, while use of $\mathrm{E}$ alone for 5 to 10 years was associated with an increased risk of both cancer types, albeit the risk for lobular tumors was stronger $(\mathrm{RR}=1.30$; 95\% CI, 1.171.45 ; and $\mathrm{RR}=1.76 ; 95 \% \mathrm{CI}, 1.34-2.34$, for ductal and lobular cancers, respectively). Current E+P use was associated with increased risks of both subtypes of breast cancer, although we found a stronger RR for lobular than ductal cancers within each duration category. Specifically, the RRs for $<5$ years of use vs. no use were 1.56 (95\% CI, 1.36-1.78) for ductal cancer and 2.16 (95\% CI, 1.52-3.06) for lobular cancer, while the RRs for 5-10 years of use were 1.75 (95\% CI, 1.57-1.95) and 3.12 (95\% CI, 2.41-4.05) for ductal and lobular cancers, respectively.

\section{Nonreproductive exposures}

BMI was positively associated with risk of both subtypes $(P$-het $=0.20)$ (Table 2). Compared to women with BMI $<21$, women with BMI $\geq 30$ had RRs of 1.60 (95\% CI, 1.42-1.80) and 1.47 (95\% CI, 1.08-2.00) for ductal and lobular cancers, respectively. In contrast, BMI at age 18 was inversely associated with risk of both subtypes (RR $\geq 23$ vs. 19 to $<21=0.74 ; 95 \% \mathrm{CI}, 0.67-0.81$ for ductal; and 0.69; $95 \%$ CI, 0.54-0.88 for lobular cancers; $P$-het = 0.16). For each five-unit increase in BMI at age 18 , there was a significant $23 \%$ and $22 \%$ decrease in risk of ductal and lobular cancers, respectively. We [15] and others $[16,17]$ have shown that obesity is more strongly associated with breast cancer risk among women who have never used PMH. In a supplementary analysis among never users, there was significant heterogeneity in the association between BMI and risk by tumor subtype $(P$-het $=0.02)$ with a stronger positive association for ductal vs. lobular tumors (RR, BMI $\geq 30$ vs. $<21=2.11$; 95\% CI, 1.71-2.60; and RR = 1.70; 95\% CI, 0.97-2.98, respectively). However, the sample size was reduced (1,596 ductal and 177 lobular cases).

The positive associations for family history of breast cancer and a personal history of BBD were similar across the two subtypes (Table 2). There was suggestion of a stronger positive association between increasing daily alcohol intake and risk of lobular cancer $(P$-het $=$ 0.11 for each five-unit increase).

\section{ER and PR status}

Since lobular tumors are more likely to be ER-positive and PR-positive than ductal cancers, we restricted analyses to ER-positive and PR-positive tumors in secondary analyses to address whether our observations were driven by differential proportions of hormone receptor positivity between ductal and lobular tumors. A total of 2,233 tumors ER-positive and PR-positive tumors were included in this analysis (Table 3). In general, the results were similar to those we observed in the analysis among all tumors. Among the reproductive and hormonal risk factors, there were still significant differences for the associations with age at menarche, AFB and PMH use, but not for age, nulliparity, parity, age at menopause or menopausal type $(P$-het $\geq 0.16)$. Nevertheless, there was significant heterogeneity for the relationship with increasing parity when we modeled this exposure continuously $(P$-het $=0.05)$. Similar to the analysis including the entire cohort, the protective effect of parity was 
Table 2 Association between various reproductive and nonreproductive exposures and risk of postmenopausal breast cancer by histologic subtype among 107,759 women in the Nurses' Health Study ${ }^{a}$

\begin{tabular}{|c|c|c|c|c|c|}
\hline \multirow[b]{2}{*}{ Reproductive or hormonal exposures } & \multicolumn{2}{|c|}{ Ductal $(n=4,655)$} & \multicolumn{2}{|c|}{ Lobular $(n=659)$} & \multirow[b]{2}{*}{$P$-heterogeneity ${ }^{b}$} \\
\hline & Cases (n) & RR $(95 \% \mathrm{Cl})$ & Cases $(n)$ & RR $(95 \% \mathrm{Cl})$ & \\
\hline Age $(\text { per year) })^{c}$ & 4,655 & $1.03(1.03-1.04)$ & 659 & $1.04(1.03-1.06)$ & 0.18 \\
\hline Age at menarche (per year) ${ }^{c}$ & 4,655 & $0.98(0.96-1.00)$ & 659 & $0.92(0.87-0.97)$ & 0.03 \\
\hline Parous & 4,220 & 1.00 (ref) & 610 & 1.00 (ref) & \\
\hline Nulliparous & 437 & $1.26(1.12-1.41)$ & 49 & $1.22(0.87-1.71)$ & 0.87 \\
\hline \multicolumn{6}{|l|}{ Age at first birth (AFB) } \\
\hline AFB $<25$ & 2,354 & 1.00 (ref) & 268 & 1.00 (ref) & \\
\hline AFB 25-29 & 1,741 & $1.11(2.04-1.19)$ & 282 & $1.63(1.37-1.96)$ & \\
\hline AFB 30-34 & 425 & $1.21(1.09-1.35)$ & 86 & $2.31(1.79-2.99)$ & \\
\hline AFB $\geq 35$ & 137 & $1.31(1.10-1.57)$ & 23 & $2.10(1.35-3.26)$ & $<0.001$ \\
\hline AFB, continuous, RR $(P \text { trend })^{c}$ & & $1.12(<0.001)$ & & $1.48(<0.001)$ & $<0.001$ \\
\hline \multicolumn{6}{|l|}{ Parity } \\
\hline Parity $=1$ & 813 & 1.00 (ref) & 100 & 1.00 (ref) & \\
\hline Parity $=2$ & 1,171 & $0.99(0.91-1.07)$ & 180 & $0.94(0.76-1.16)$ & \\
\hline Parity $=3$ & 1,269 & $1.04(0.96-1.13)$ & 163 & $0.88(0.71-1.09)$ & \\
\hline Parity $\geq 4$ & 1,404 & $0.91(0.82-1.00)$ & 216 & $0.96(0.75-1.24)$ & 0.35 \\
\hline Parity, continuous, RR ( $P$ trend) $)^{d}$ & & $0.97(0.01)$ & & $1.05(0.11)$ & 0.02 \\
\hline \multicolumn{6}{|l|}{ Postmenopausal hormone use } \\
\hline Never used & 1,616 & 1.00 (ref) & 181 & 1.00 (ref) & \\
\hline Past use & 1,165 & $1.05(0.97-1.14)$ & 150 & $1.11(0.88-1.39)$ & \\
\hline Current use, estrogen alone $<5$ years & 143 & $1.07(0.90-1.28)$ & 24 & $1.56(1.01-2.42)$ & \\
\hline Current use, estrogen plus progesterone $<5$ years & 283 & $1.56(1.36-1.78)$ & 42 & $2.16(1.52-3.06)$ & \\
\hline Current use, other $\leq 10$ years & 267 & $1.31(1.15-1.49)$ & 46 & $1.95(1.40-2.71)$ & \\
\hline Current use, estrogen alone 5-10 years & 518 & $1.30(1.17-1.45)$ & 93 & $1.76(1.34-2.34)$ & \\
\hline Current use, estrogen + progesterone 5-10 years & 463 & $1.75(1.57-1.95)$ & 99 & $3.12(2.41-4.05)$ & $<0.001$ \\
\hline Estrogen alone, continuous, RR $(P \text { trend })^{\mathrm{e}}$ & & $1.00(0.008)$ & & $1.00(0.24)$ & 1.00 \\
\hline Estrogen + progesterone, continuous, RR $(P \text { trend })^{e}$ & & $1.02(<0.001)$ & & $1.03(<0.001)$ & 0.43 \\
\hline Other, continuous, RR $(P \text { trend })^{e}$ & & $1.00(0.45)$ & & $1.01(0.30)$ & 0.52 \\
\hline Age at menopause (per year) ${ }^{c}$ & 4,655 & $1.01(1.00-1.01)$ & 659 & $1.01(1.00-1.02)$ & 0.45 \\
\hline \multicolumn{6}{|l|}{ Menopausal type } \\
\hline Natural or radiation-induced & 2,958 & 1.00 (ref) & 391 & 1.00 (ref) & \\
\hline Surgical with two ovaries removed & 667 & $0.80(0.73-0.89)$ & 101 & $1.00(0.78-1.29)$ & \\
\hline Surgical with one or no ovaries removed & 559 & $0.87(0.79-0.96)$ & 100 & $1.21(0.95-1.53)$ & 0.08 \\
\hline \multicolumn{6}{|l|}{ Nonreproductive exposures } \\
\hline \multicolumn{6}{|l|}{ Body mass index (BMI) } \\
\hline$<21$ & 473 & 1.00 (ref) & 70 & 1.00 (ref) & \\
\hline 21 to less than 23 & 719 & $1.15(1.02-1.29)$ & 104 & $1.11(0.82-1.50)$ & \\
\hline 23 to less than 25 & 858 & $1.21(1.08-1.35)$ & 122 & $1.14(0.85-1.54)$ & \\
\hline 25 to less than 30 & 1,590 & $1.41(1.27-1.57)$ & 225 & $1.33(1.01-1.75)$ & \\
\hline$\geq 30$ & 926 & $1.60(1.42-1.80)$ & 124 & $1.47(1.08-2.00)$ & 0.20 \\
\hline BMl, continuous, RR $(P \text { trend })^{f}$ & & $1.14(<0.001)$ & & $1.12(0.009)$ & 0.75 \\
\hline \multicolumn{6}{|l|}{$\mathrm{BMl}$ at age 18} \\
\hline$<19$ & 839 & $1.07(0.98-1.16)$ & 114 & $1.00(0.79-1.25)$ & \\
\hline 19 to less than 21 & 1,506 & 1.00 (ref) & 221 & 1.00 (ref) & \\
\hline 21 to less than 23 & 959 & $0.83(0.77-0.90)$ & 148 & $0.88(0.71-1.09)$ & \\
\hline$\geq 23$ & 744 & $0.74(0.67-0.81)$ & 99 & $0.69(0.54-0.88)$ & 0.16 \\
\hline BMl at age 18 , continuous, RR $(P \text { trend })^{f}$ & & $0.77(<0.001)$ & & $0.78(0.003)$ & 0.80 \\
\hline \multicolumn{6}{|l|}{ Alcohol intake (g/day) } \\
\hline 0 & 2,552 & 1.00 (ref) & 334 & 1.00 (ref) & \\
\hline$<5$ & 876 & $1.15(1.06-1.24)$ & 131 & $1.30(1.05-1.59)$ & \\
\hline
\end{tabular}




\begin{tabular}{|c|c|c|c|c|c|}
\hline 5 to less than 15 & 765 & $1.22(1.12-1.32)$ & 113 & $1.34(1.08-1.67)$ & \\
\hline$\geq 15$ & 462 & $1.31(1.19-1.45)$ & 81 & $1.75(1.36-2.24)$ & 0.20 \\
\hline Alcohol intake, continuous, RR $(P \text { trend })^{9}$ & & $1.04(<0.001)$ & & $1.07(<0.001)$ & 0.11 \\
\hline \multicolumn{6}{|l|}{ Family history of breast cancer } \\
\hline No & 3,805 & 1.00 (ref) & 544 & 1.00 (ref) & \\
\hline Yes & 850 & $1.55(1.44-1.67)$ & 115 & $1.41(1.15-1.73)$ & 0.39 \\
\hline \multicolumn{6}{|l|}{ Personal history of benign breast disease } \\
\hline No & 2,294 & 1.00 (ref) & 298 & 1.00 (ref) & \\
\hline Yes & 2,361 & $1.47(1.38-1.56)$ & 361 & $1.60(1.37-1.88)$ & 0.32 \\
\hline
\end{tabular}

${ }^{a}$ Estimates adjusted for all variables presented in the table. ${ }^{b} P$ value from likelihood ratio test comparing, for each covariate, the model with separate estimates for the ductal and lobular histologic subtypes to the model with a single estimate across the two subtypes. ${ }^{\mathrm{C}}$ Risk ratio (RR) for each 5 -year increase in age among parous women. ${ }^{\mathrm{d} R}$ for each child among parous women. ${ }^{\mathrm{e} R R}$ for each 5 -year increase in use. ${ }^{\mathrm{f} R R}$ for each five-unit increase in BMI (kg/m ${ }^{2}$ ). ${ }^{9} \mathrm{RR}$ for each five-unit increase in daily alcohol consumption (g/day). $95 \% \mathrm{Cl}, 95 \%$ confidence interval.

stronger for ductal vs. lobular tumors. For the nonreproductive exposures, there was significant heterogeneity for the association with BMI at 18 years of age $(P$-het $=$ 0.03 ) and increasing daily alcohol intake $(P$-het $=0.02)$, with a stronger association for lobular cancers but no heterogeneity of effect for adult BMI, family history of breast cancer or history of BBD ( $P$-het $\geq 0.07)$.

\section{Discussion}

The results from this large prospective study further substantiate that well-established breast cancer risk factors differentially affect risk on the basis of tumor histology. Specifically, age at menarche, AFB and PMH use were more strongly associated with lobular versus ductal tumors, while there was no evidence for heterogeneity for age at menopause, nulliparity, parity, menopausal type, alcohol consumption, adult BMI, BMI at age 18, family history of breast cancer and a personal history of BBD. Collectively, these data suggest different etiologies among the tumor subtypes and that lobular carcinomas may represent a more hormonally responsive subtype. When our analysis was limited to ER-positive and PRpositive tumors, the findings were maintained, suggesting true differences in the underlying tumor biology and not a result of differential rates of ER and PR positivity.

A recent prospective analysis examined reproductive and hormonal factors and risk of breast cancer by histology among 17,923 ductal and 3,332 lobular cancers from the Million Women Study [18]. Similar to our results, the effect of age at menarche was greater for lobular compared with ductal tumors (RR per 5-year increase $=0.65$ for lobular and 0.93 for ductal). Further, in the Reeves et al. [18] meta-analysis of six cohort and three case control studies, the summary estimates were similar. No formal tests for heterogeneity were performed. Although suggestive of differences in the effect of age at menarche by histologic subtype, most studies had low power and only one study was restricted to postmenopausal women [19]. Overall, prior studies and our observations support a stronger protective effect of a later age at menarche for lobular cancer.

The overall RRs for AFB $\geq 30$ vs. $<20$ from a meta-analysis of nine studies (six cohort and three case control) were 1.24 for ductal cancer and 1.66 for lobular cancer; however, individually, most studies had limited power, and only the Million Women Study reported a statistically significant difference in the RRs by subtype [18]. Phipps et al. [20] recently reported no difference in risk with AFB across subtypes. In our analysis, nulliparity was associated with an increased risk of both cancer subtypes, while we observed significant heterogeneity in the association only for AFB, but not for parity per se. When we modeled the continuous values, the $P$ trend for increasing parity was significant only for ductal tumors; however, the effect of AFB was strongest for lobular tumors. We cannot preclude that the discrepancy between the categorical and continuous results for parity may be attributed to residual confounding by AFB, which does not occur when modeled as categorical or nonoverlapping variables. In other words, it may be that women with higher parity are also likely to have a later AFB. Our RR estimates for a 5-year delay in AFB were 1.48 for lobular cancer vs. 1.12 for ductal cancer. Other studies have reported no difference in risk for parity by subtype $[18,21,22]$. Prior reports are in agreement with our findings regarding parity. A recent prospective analysis including 1,211,238 women reported a lower risk of ductal but not lobular cancers with parity [20]. Two additional reports have suggested that increasing parity was associated with decreased risk of ductal but not lobular cancers, although one study did not report $P$ values [23] and the association was not statistically significant in the second study [24]. On the basis of our data and prior data, a later AFB and not parity per se may play an important etiological role for lobular cancers, while both AFB and number of births appear to 
Table 3 Association between various reproductive and non-reproductive exposures and risk of postmenopausal breast cancer by histologic subtype among 107,759 women in the Nurses' Health Study, ER-positive and PR-positive tumors only

\begin{tabular}{|c|c|c|c|c|c|}
\hline \multirow[b]{2}{*}{ Reproductive or hormonal exposures } & \multicolumn{2}{|c|}{ Ductal $(n=4,655)$} & \multicolumn{2}{|c|}{ Lobular $(n=659)$} & \multirow[b]{2}{*}{$P$-heterogeneity } \\
\hline & Cases (n) & $\mathrm{RR}(95 \% \mathrm{Cl})$ & Cases (n) & RR (95\% Cl) & \\
\hline Age $(\text { per year) })^{c}$ & 1,947 & $1.03(1.02-1.04)$ & 286 & $1.04(1.02-1.06)$ & 0.71 \\
\hline Age at menarche (per year) $)^{c}$ & 1,947 & $0.99(0.96-1.02)$ & 286 & $0.87(0.80-0.95)$ & 0.005 \\
\hline Parous & 1,795 & 1.00 (ref) & 276 & 1.00 (ref) & \\
\hline Nulliparous & 200 & $1.17(0.94-1.47)$ & 17 & $0.90(0.47-1.72)$ & 0.45 \\
\hline \multicolumn{6}{|l|}{ Age at first birth (AFB) } \\
\hline AFB $<25$ & 1,040 & 1.00 (ref) & 111 & 1.00 (ref) & \\
\hline AFB 25-29 & 730 & $1.06(0.95-1.17)$ & 131 & $1.82(1.39-2.38)$ & \\
\hline AFB 30-34 & 174 & $1.09(0.92-1.29)$ & 41 & $2.62(1.78-3.88)$ & \\
\hline AFB $\geq 35$ & 51 & $1.02(0.76-1.37)$ & 10 & $2.10(1.04-4.21)$ & $<0.001$ \\
\hline AFB, continuous, RR $(P \text { trend })^{c}$ & & $1.11(0.004)$ & & $1.56(<0.001)$ & $<0.001$ \\
\hline \multicolumn{6}{|l|}{ Parity } \\
\hline Parity = 1 & 360 & 1.00 (ref) & 48 & 1.00 (ref) & \\
\hline Parity $=2$ & 476 & $0.82(0.68-0.99)$ & 72 & $0.71(0.46-1.10)$ & \\
\hline Parity $=3$ & 545 & $0.90(0.75-1.08)$ & 69 & $0.71(0.45-1.11)$ & \\
\hline Parity $\geq 4$ & 614 & $0.80(0.67-0.97)$ & 104 & $0.94(0.61-1.46)$ & 0.09 \\
\hline Parity, continuous, RR ( $P$ trend) $)^{d}$ & & $0.98(0.15)$ & & $1.06(0.12)$ & 0.05 \\
\hline \multicolumn{6}{|l|}{ Postmenopausal hormone use } \\
\hline Never used & 738 & 1.00 (ref) & 90 & 1.00 (ref) & \\
\hline Past use & 549 & $1.09(0.97-1.22)$ & 73 & $1.18(0.85-1.63)$ & \\
\hline Current use, estrogen alone $<5$ years & 59 & $1.01(0.77-1.32)$ & 12 & $1.64(0.88-3.05)$ & \\
\hline Current use, estrogen plus progesterone $<5$ years & 155 & $1.74(1.45-2.08)$ & 29 & $2.95(1.90-4.57)$ & \\
\hline Current use, other $\leq 10$ years & 91 & $1.28(1.03-1.59)$ & 14 & $1.82(1.05-3.17)$ & \\
\hline Current use, estrogen alone 5-10 years & 118 & $1.36(1.11-1.67)$ & 26 & $2.49(1.57-3.97)$ & \\
\hline Current use, estrogen + progesterone 5-10 years & 180 & $2.05(1.73-2.43)$ & 35 & $3.37(2.23-5.08)$ & $<0.001$ \\
\hline Estrogen alone, continuous, RR ( $P$ trend) $)^{e}$ & & $1.00(0.006)$ & & $1.00(0.63)$ & 0.53 \\
\hline Estrogen + progesterone, continuous, RR $(P \text { trend })^{e}$ & & $1.03(<0.001)$ & & $1.03(<0.001)$ & 0.24 \\
\hline Other, continuous, RR $(P \text { trend })^{\mathrm{e}}$ & & $1.00(0.71)$ & & $1.01(0.36)$ & 0.44 \\
\hline Age at menopause (per year) ${ }^{c}$ & 1,947 & $1.00(1.00-1.01)$ & 286 & $1.02(1.00-1.03)$ & 0.16 \\
\hline \multicolumn{6}{|l|}{ Menopausal type } \\
\hline Natural or radiation-induced & 1,337 & 1.00 (ref) & 185 & 1.00 (ref) & \\
\hline Surgical with two ovaries removed & 194 & $0.75(0.64-0.88)$ & 29 & $0.89(0.59-1.36)$ & \\
\hline Surgical with one or no ovaries removed & 202 & $0.86(0.73-1.00)$ & 35 & $1.10(0.75-1.60)$ & 0.63 \\
\hline \multicolumn{6}{|l|}{ Nonreproductive exposures } \\
\hline \multicolumn{6}{|l|}{ Body mass index (BMI) } \\
\hline$<21$ & 178 & 1.00 (ref) & 26 & 1.00 (ref) & \\
\hline 21 to less than 23 & 251 & $1.05(0.87-1.27)$ & 37 & $1.08(0.66-1.78)$ & \\
\hline 23 to less than 25 & 347 & $1.27(1.06-1.52)$ & 51 & $1.32(0.82-2.11)$ & \\
\hline 25 to less than 30 & 677 & $1.54(1.30-1.82)$ & 98 & $1.49(0.96-2.31)$ & \\
\hline$\geq 30$ & 465 & $2.00(1.67-2.39)$ & 67 & $1.87(1.16-3.01)$ & 0.23 \\
\hline BMl, continuous, RR $(P \text { trend })^{f}$ & & $1.23(<0.001)$ & & $1.25(<0.001)$ & 0.79 \\
\hline \multicolumn{6}{|l|}{$\mathrm{BMl}$ at age 18} \\
\hline$<19$ & 355 & $1.18(1.04-1.35)$ & 51 & $1.42(0.97-2.01)$ & \\
\hline 19 to less than 21 & 593 & 1.00 (ref) & 76 & 1.00 (ref) & \\
\hline 21 to less than 23 & 399 & $0.84(0.74-0.95)$ & 71 & $1.22(0.89-1.67)$ & \\
\hline$\geq 23$ & 354 & $0.81(0.71-0.93)$ & 49 & $0.89(0.61-1.30)$ & 0.03 \\
\hline $\mathrm{BMI}$ at age 18 , continuous, $\mathrm{RR}(P \text { trend })^{\mathrm{f}}$ & & $0.80(<0.001)$ & & $0.81(0.08)$ & 0.95 \\
\hline \multicolumn{6}{|l|}{ Alcohol intake (g/day) } \\
\hline 0 & 1,062 & 1.00 (ref) & 148 & 1.00 (ref) & \\
\hline
\end{tabular}


Table 3 Association between various reproductive and non-reproductive exposures and risk of postmenopausal breast cancer by histologic subtype among 107,759 women in the Nurses' Health Study, ER-positive and PR-positive tumors only ${ }^{\mathrm{a}}$ (Continued)

\begin{tabular}{|c|c|c|c|c|c|}
\hline$<5$ & 358 & $1.16(1.03-1.31)$ & 47 & $1.11(0.80-1.55)$ & \\
\hline 5 to less than 15 & 341 & $1.40(1.23-1.58)$ & 51 & $1.52(1.10-2.10)$ & \\
\hline$\geq 15$ & 186 & $1.37(1.17-1.61)$ & 40 & $2.28(1.60-3.24)$ & 0.07 \\
\hline Alcohol intake, continuous, RR $(P \text { trend })^{9}$ & & $1.05(<0.001)$ & & $1.12(<0.001)$ & 0.02 \\
\hline \multicolumn{6}{|l|}{ Family history of breast cancer } \\
\hline No & 1,553 & 1.00 (ref) & 227 & 1.00 (ref) & \\
\hline Yes & 394 & $1.71(1.53-1.91)$ & 59 & $1.80(1.35-2.39)$ & \\
\hline Personal history of benign breast disease & & & & & 0.76 \\
\hline No & 972 & 1.00 (ref) & 142 & 1.00 (ref) & \\
\hline Yes & 975 & $1.43(1.30-1.56)$ & 144 & $1.41(1.10-1.78)$ & 0.91 \\
\hline
\end{tabular}

${ }^{a}$ Estimates adjusted for all variables presented in the table. ${ }^{b} P$ value from likelihood ratio test comparing, for each covariate, the model with separate estimates

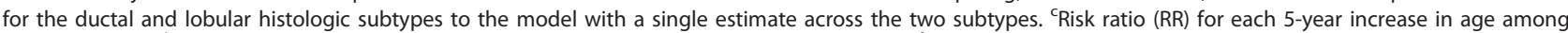
parous women. ${ }^{d} \mathrm{RR}$ for each child among parous women. ${ }^{\mathrm{e} R}$ for each 5 -year increase in use. ${ }^{\mathrm{f} R}$ for each five-unit increase in BMl (kg/m ${ }^{2}$ ). ${ }^{9} \mathrm{RR}$ for each five-unit increase in daily alcohol consumption (g/day).

be important for ductal carcinomas. Similar to our findings, most prior reports of the relationship between age at menopause or menopausal status and risk have reported no significant heterogeneity by histology $[18,21,23,25,26]$.

To date, 10 case control and 7 cohort studies have examined the relationship between PMH use and risk of developing ductal and lobular carcinoma $[7,20]$. Of these, all but two cohort studies reported a stronger increased risk for lobular compared with ductal carcinoma $[27,28]$. In general, most studies have shown that combined $\mathrm{E}+\mathrm{P}$ was more strongly related to risk of lobular vs. ductal carcinoma than use of $\mathrm{E}$ alone $[7,29]$. Lobular cancers are more likely to be ER-positive and/ or PR-positive than ductal tumors [30,31]. Thus, it is not surprising that the effect of $\mathrm{PMH}$ may be strongest for a hormone receptor-positive tumor. In fact, a recent study reporting a decrease in the incidence of invasive cancers, particularly a decline in lobular carcinomas [32], attributed this change to the concurrent decrease in PMH use [33] following publication of the results from the Women's Health Initiative [34]. Unlike what we observed among all tumors, the association with PMH did not differ significantly by histologic subtype when restricted to ER-positive and PR-positive lobular and ductal tumors; however, this could be attributed to the smaller case numbers, since the association was still suggestively stronger for lobular tumors.

Fewer studies have examined the relationship between duration of hormone use and risk [7,23,29,35-38]. In the Million Women Study, Reeves et al. [29] reported no significant difference in risk of ductal, lobular or tubular cancer with increasing duration of use. Results from the French E3N cohort also suggested no significant heterogeneity [38]. Calle et al. [7] reported an increased risk with $\geq 2$ years of use among current users for both ductal and lobular cancers. In contrast, $\mathrm{E}$ alone was associated with an increased risk of lobular cancer after 5 years of use, but not with risk of ductal cancer; however, use of $\mathrm{E}$ alone for 5-10 years was associated with risk of both cancer types, although the association was stronger for lobular tumors. Similarly, Li et al. [35] documented an increased risk of both histologic subtypes with $\geq 3$ years of use of E+P. Other case control studies have also found an increased risk of lobular cancer with longer duration of combined E+P use [10,36,37]. With our large study population and repeated assessment of PMH use, our study is adequately powered to assess a role of both timing and duration of PHH use. We similarly observed a stronger association with use of combined $\mathrm{E}+\mathrm{P}$ and the lobular type. Although there was no significant heterogeneity in the results when we modeled PMH duration as a continuous variable, this was expected, since we previously reported that breast cancer risk is increased only with long-term use (for example, at least 5 years) [39]. Nonetheless, others have shown a significant increase in risk with shorter durations of use $[7,28,40]$.

Epidemiological studies have demonstrated a positive association between BMI and postmenopausal breast cancer risk [41], although for the most part anthropometric factors appear to be similarly related to risk by histology in some $[8,25]$ but not all studies [42]. Despite this, BMI was more strongly associated, although not statistically different, with ductal cancer compared with lobular cancer in one study [21], while another group reported an inverse association between BMI and mixed ductal-lobular carcinomas $(P$-het $=0.008)$, but no significant associations for the other subtypes [26]. We did not observe significant heterogeneity for the association between BMI and risk of cancer by subtype.

To our knowledge, ours is the first study that has evaluated an association between BMI at age 18 and risk 
of postmenopausal breast cancer by histologic subtype. In general, adolescent obesity is inversely associated with breast cancer risk [41]. In a prospective analysis of the NHS, we previously reported that higher BMI at age 18 was associated with lower breast cancer incidence prior to and after menopause [15]. In the current study, the inverse association between BMI at 18 was similar for ductal and lobular cancers.

Two prior studies reported a significant positive association between alcohol consumption and risk of breast cancer overall, which was stronger for lobular compared with ductal cancer among postmenopausal women (odds ratio $(\mathrm{OR})=1.8$ vs. 1.2 [43] and 1.5 vs. 1.2 [26] for lobular and ductal cancers, respectively). In a third study, Rosenberg et al. [23] found a strong association between alcohol consumption and risk of tubular but not ductal or lobular cancers. Although we did not observe significant heterogeneity between daily alcohol consumption and risk overall, we did observe a positive association between increasing intake and risk which was suggestively stronger for lobular cancers $(P$-het $=$ 0.11 ). Despite these findings, there was significant heterogeneity for this association when we limited the analysis to ER-positive and PR-positive tumors ( $P$-het $=$ $0.02)$. Given the inconsistent results, further research is needed for this exposure.

In our analysis, family history of breast cancer and a personal history of BBD were similarly associated with increased risk of breast cancer, regardless of subtype. Three prior studies have evaluated the relationship between family history and risk by histology $[9,20,26]$. Recently, Phipps et al. [20] reported similar positive associations across subtypes in their cohort study. In a population-based case control analysis, family history was associated with a twofold increased risk of breast cancer across all histologic subtypes except for mucinous tumors [26], while family history was similarly associated with a two- to threefold increase in risk of all subtypes except for tubular carcinomas [9]. No confidence intervals or formal tests for heterogeneity were reported in the latter study. To our knowledge, two prior studies have evaluated the relationship between BBD and breast cancer risk stratified by histologic subtype [20,23]. A previous operation for BBD was associated with a slightly higher risk of lobular cancer $(\mathrm{OR}=$ 1.9) compared with ductal cancer $(\mathrm{OR}=1.5)$, although this difference did not achieve statistical significance. In contrast, a recent cohort study found similar significant positive associations with BBD across subtypes with increasing density (hazard ratio for highest density vs. reference for both ductal and lobular cases was 1.62) [20]. On the whole, there do not appear to be large differences in the relationship between family history of breast cancer or personal history of BBD by histology.
Overall, the relationship between the exposures evaluated in the current study and the risk of breast cancer was within the expected range and both subtypes showed similar directions; however, the associations for age at menarche, AFB and PMH use were stronger for risk of lobular vs. ductal tumors. Since lobular tumors are more often hormone receptor-positive, it is not entirely unexpected that various hormonal or reproductive risk factors may be more strongly associated with this subtype. The proposed mechanism underlying the association between an earlier age at menarche and risk likely is via its effect on the number of lifetime ovulatory cycles, which in turn influences lifetime exposure to endogenous ovarian hormones [44]. Parity not only leads to substantial changes in hormone levels but also induces differentiation of terminal duct lobular units, making the breast epithelial cells less susceptible to carcinogenic insult [45]. Given that both exogenous and endogenous hormones have been shown to strongly influence breast cancer risk, an altered sex hormone profile associated with $\mathrm{PMH}$ use as an exogenous hormone source would also be expected to increase risk [2]. Collectively, the data suggest that lobular breast tumors are more hormonally responsive than ductal breast tumors, thus making this histologic subtype more responsive to hormonal stimulation [9]. Furthermore, exposure to reproductive hormones (that is, estrogen or progesterone) has been shown to promote lobular rather than ductal differentiation, subsequently increasing the number of lobular cells at risk [9]. In addition, various groups have shown differences in gene expression between these two histologic subtypes, providing insight into the biology of these tumors, which may in turn be utilized as diagnostic or therapeutic targets $[46,47]$. Future studies should continue to investigate the biological basis for the reported differential relationships.

Major strengths of our study include the large number of participants and high participation rate, resulting in adequate statistical power to conduct stratified analyses. Further, the prospective nature of the NHS cohort allows for the analysis of repeated measures of most exposures and confounders, limiting the effect of measurement error. In addition, the methods used in this analysis allowed for the estimation of separate associations with each subtype simultaneously, as well as formal tests for differences in risk across subtypes. Although our analysis included a large number of invasive breast cancer cases, we did not have enough cases to assess risk with less common histologic subtypes (for example, tubular). Further, our analysis of ER-positive and PR-positive tumors was less well-powered, given that hormone receptor status was not available for all cases. An additional limitation was that we classified histologies on the basis of a review of pathology reports 
and did not conduct a centralized pathology review. This could lead to nondifferential misclassification of tumor histology and attenuate the associations.

\section{Conclusions}

In summary, the results from this study provide evidence that some reproductive or hormonal and nonreproductive factors are differentially associated with risk of postmenopausal breast cancer on the basis of histologic subtype. For the most part, our results are consistent with prior reports, complementing the growing body of evidence suggesting etiologic heterogeneity between ductal and lobular tumors. Future risk factor analyses should continue to investigate associations stratified by histology.

\begin{abstract}
Abbreviations
AFB: age at first birth; BBD: benign breast disease; BMl: body mass index; $\mathrm{Cl}$ : confidence interval; DCIS: ductal carcinoma in situ; E: estrogen; E + P: estrogen and progesterone; ER: estrogen receptor; NHS: Nurses' Health Study; OR: odds ratio; $P$-het: $P$ value for heterogeneity; $\mathrm{PMH}$ : postmenopausal hormones; PR: progesterone receptor; RR: relative risk.
\end{abstract}

\section{Acknowledgements}

The authors thank the study participants of the Nurses' Health Study for their dedication to this study and their contribution to this research. This research was supported by research grant P01 CA87969 from the National Cancer Institute. JK is a Research Fellow of the Canadian Cancer Society supported through an award from the National Cancer Institute of Canada. MAG was supported by training grant T32 CA009001 from the National Cancer Institute.

\section{Author details}

${ }^{1}$ Channing Laboratory, Department of Medicine, Brigham and Women's Hospital and Harvard Medical School, 181 Longwood Avenue, 3rd Floor, Boston, MA 02115, USA. ²Department of Medical Oncology, Dana-Farber Cancer Institute, 44 Binney Street, Boston, MA 02115, USA. ${ }^{3}$ Department of Epidemiology, Harvard School of Public Health, 677 Huntington Avenue, Boston, MA 02115, USA. ${ }^{4}$ Department of Biostatistics, Harvard School of Public Health, 655 Huntington Avenue, SPH2, 4th Floor, Boston, MA 02115, USA.

\section{Authors' contributions}

JK helped to design, analyze and interpret the data and drafted the initial manuscript. WYC helped to design, analyze and interpret the data and did critical revisions of the manuscript. MAG helped with statistical analysis and data interpretation. SEH and SST both helped analyze and interpret the data and critically revised the manuscript. BAR helped with statistical analysis, interpreted the data and critically revised the manuscript. All authors read and approved the final manuscript.

\section{Competing interests}

The authors declare that they have no competing interests.

Received: 29 June 2010 Revised: 22 October 2010

Accepted: 8 December 2010 Published: 8 December 2010

\section{References}

1. Kelsey JL, Gammon MD, John EM: Reproductive factors and breast cancer. Epidemiol Rev 1993, 15:36-47.

2. Bernstein L: Epidemiology of endocrine-related risk factors for breast cancer. J Mammary Gland Biol Neoplasia 2002, 7:3-15.

3. Li Cl, Anderson BO, Daling JR, Moe RE: Trends in incidence rates of invasive lobular and ductal breast carcinoma. JAMA 2003, 289:1421-1424.
4. Cocquyt V, Van Belle S: Lobular carcinoma in situ and invasive lobular cancer of the breast. Curr Opin Obstet Gynecol 2005, 17:55-60.

5. Arpino G, Bardou VJ, Clark GM, Elledge RM: Infiltrating lobular carcinoma of the breast: tumor characteristics and clinical outcome. Breast Cancer Res 2004, 6:R149-R156.

6. Korhonen T, Huhtala H, Holli K: A comparison of the biological and clinical features of invasive lobular and ductal carcinomas of the breast. Breast Cancer Res Treat 2004, 85:23-29.

7. Calle EE, Feigelson HS, Hildebrand JS, Teras LR, Thun MJ, Rodriguez C: Postmenopausal hormone use and breast cancer associations differ by hormone regimen and histologic subtype. Cancer 2009, 115:936-945.

8. Rosenberg LU, Einarsdottir K, Friman El, Wedren S, Dickman PW, Hall P, Magnusson C: Risk factors for hormone receptor-defined breast cancer in postmenopausal women. Cancer Epidemiol Biomarkers Prev 2006, 15:2482-2488.

9. Stalsberg $H$, Thomas DB, Noonan EA: Histologic types of breast carcinoma in relation to international variation and breast cancer risk factors. WHO Collaborative Study of Neoplasia and Steroid Contraceptives. Int J Cancer 1989, 44:399-409.

10. Daling JR, Malone KE, Doody DR, Voigt LF, Bernstein L, Coates RJ, Marchbanks PA, Norman SA, Weiss LK, Ursin G, Berlin JA, Burkman RT, Deapen D, Folger SG, McDonald JA, Simon MS, Strom BL, Wingo PA, Spirtas R: Relation of regimens of combined hormone replacement therapy to lobular, ductal, and other histologic types of breast carcinoma. Cancer 2002, 95:2455-2464.

11. Colditz GA: The Nurses' Health Study: a cohort of US women followed since 1976. J Am Med Womens Assoc 1995, 50:40-44.

12. Colditz GA, Manson JE, Hankinson SE: The Nurses' Health Study: 20-year contribution to the understanding of health among women. J Womens Health 1997, 6:49-62.

13. Colditz GA, Hankinson SE: The Nurses' Health Study: lifestyle and health among women. Nat Rev Cancer 2005, 5:388-396.

14. Lunn M, McNeil D: Applying Cox regression to competing risks. Biometrics 1995, 51:524-532.

15. Huang Z, Hankinson SE, Colditz GA, Stampfer MJ, Hunter DJ, Manson JE, Hennekens CH, Rosner B, Speizer FE, Willett WC: Dual effects of weight and weight gain on breast cancer risk. JAMA 1997, 278:1407-1411.

16. Collaborative Group on Hormonal Factors in Breast Cancer: Breast cancer and hormone replacement therapy: collaborative reanalysis of data from 51 epidemiological studies of 52,705 women with breast cancer and 108,411 women without breast cancer. Lancet 1997, 350:1047-1059.

17. Morimoto LM, White E, Chen Z, Chlebowski RT, Hays J, Kuller L, Lopez AM, Manson J, Margolis KL, Muti PC, Stefanick ML, McTiernan A: Obesity, body size, and risk of postmenopausal breast cancer: the Women's Health Initiative (United States). Cancer Causes Control 2002, 13:741-751.

18. Reeves GK, Pirie K, Green J, Bull D, Beral V: Reproductive factors and specific histological types of breast cancer: prospective study and metaanalysis. Br J Cancer 2009, 100:538-544.

19. Li Cl, Malone KE, Daling JR, Potter JD, Bernstein L, Marchbanks PA, Strom BL, Simon MS, Press MF, Ursin G, Burkman RT, Folger SG, Norman S, McDonald JA, Spirtas R: Timing of menarche and first full-term birth in relation to breast cancer risk. Am J Epidemiol 2008, 167:230-239.

20. Phipps Al, Li Cl, Kerlikowske K, Barlow WE, Buist DS: Risk factors for ductal, lobular, and mixed ductal-lobular breast cancer in a screening population. Cancer Epidemiol Biomarkers Prev 2010, 19:1643-1654.

21. Li Cl, Malone KE, Porter PL, Weiss NS, Tang MT, Daling JR: Reproductive and anthropometric factors in relation to the risk of lobular and ductal breast carcinoma among women 65-79 years of age. Int J Cancer 2003, 107:647-651.

22. Wohlfahrt J, Mouridsen $H$, Andersen PK, Melbye M: Reproductive risk factors for breast cancer by receptor status, histology, laterality and location. Int J Cancer 1999, 81:49-55.

23. Rosenberg LU, Magnusson C, Lindstrom E, Wedren S, Hall P, Dickman PW: Menopausal hormone therapy and other breast cancer risk factors in relation to the risk of different histological subtypes of breast cancer: a case-control study. Breast Cancer Res 2006, 8:R11.

24. Ursin G, Bernstein L, Lord SJ, Karim R, Deapen D, Press MF, Daling JR, Norman SA, Liff JM, Marchbanks PA, Folger SG, Simon MS, Strom BL, Burkman RT, Weiss LK, Spirtas R: Reproductive factors and subtypes of breast cancer defined by hormone receptor and histology. Br J Cancer 2005, 93:364-371. 
25. García-Closas M, Brinton LA, Lissowska J, Chatterjee N, Peplonska B, Anderson WF, Szeszenia-Dabrowska N, Bardin-Mikolajczak A, Zatonski W, Blair A, Kalaylioglu Z, Rymkiewicz G, Mazepa-Sikora D, Kordek R, Lukaszek S, Sherman ME: Established breast cancer risk factors by clinically important tumour characteristics. Br J Cancer 2006, 95:123-129.

26. Li Cl, Daling JR, Malone KE, Bernstein L, Marchbanks PA, Liff JM, Strom BL, Simon MS, Press MF, McDonald JA, Ursin G, Burkman RT, Deapen D, Spirtas R: Relationship between established breast cancer risk factors and risk of seven different histologic types of invasive breast cancer. Cancer Epidemiol Biomarkers Prev 2006, 15:946-954.

27. Lee $\mathrm{S}$, Kolonel L, Wilkens L, Wan P, Henderson B, Pike M: Postmenopausal hormone therapy and breast cancer risk: the Multiethnic Cohort. Int $J$ Cancer 2006, 118:1285-1291.

28. Brinton LA, Richesson D, Leitzmann MF, Gierach GL, Schatzkin A, Mouw T, Hollenbeck AR, Lacey JV Jr: Menopausal hormone therapy and breast cancer risk in the NIH-AARP Diet and Health Study Cohort. Cancer Epidemiol Biomarkers Prev 2008, 17:3150-3160.

29. Reeves GK, Beral V, Green J, Gathani T, Bull D: Hormonal therapy for menopause and breast-cancer risk by histological type: a cohort study and meta-analysis. Lancet Oncol 2006, 7:910-918.

30. Riva C, Dainese E, Caprara G, Rocca PC, Massarelli G, Tot T, Capella C, Eusebi V: Immunohistochemical study of androgen receptors in breast carcinoma: evidence of their frequent expression in lobular carcinoma. Virchows Arch 2005, 447:695-700.

31. Li Cl, Uribe DJ, Daling JR: Clinical characteristics of different histologic types of breast cancer. Br J Cancer 2005, 93:1046-1052

32. Eheman CR, Shaw KM, Ryerson AB, Miller JW, Ajani UA, White MC: The changing incidence of in situ and invasive ductal and lobular breast carcinomas: United States, 1999-2004. Cancer Epidemiol Biomarkers Prev 2009, 18:1763-1769.

33. Clarke CA, Glaser SL, Uratsu CS, Selby JV, Kushi LH, Herrinton LJ: Recent declines in hormone therapy utilization and breast cancer incidence: clinical and population-based evidence. J Clin Oncol 2006, 24:e49-e50.

34. Rossouw JE, Anderson GL, Prentice RL, LaCroix AZ, Kooperberg C, Stefanick ML, Jackson RD, Beresford SA, Howard BV, Johnson KC, Kotchen JM, Ockene J, Writing Group for the Women's Health Initiative Investigators: Risks and benefits of estrogen plus progestin in healthy postmenopausal women: principal results from the Women's Health Initiative randomized controlled trial. JAMA 2002, 288:321-333.

35. Li Cl, Malone KE, Porter PL, Lawton TJ, Voigt LF, Cushing-Haugen KL, Lin MG, Yuan X, Daling JR: Relationship between menopausal hormone therapy and risk of ductal, lobular, and ductal-lobular breast carcinomas. Cancer Epidemiol Biomarkers Prev 2008, 17:43-50.

36. Chen CL, Weiss NS, Newcomb P, Barlow W, White E: Hormone replacement therapy in relation to breast cancer. JAMA 2002, 287:734-741

37. Li Cl, Malone KE, Porter PL, Weiss NS, Tang MT, Cushing-Haugen KL, Daling JR: Relationship between long durations and different regimens of hormone therapy and risk of breast cancer. JAMA 2003, 289:3254-3263.

38. Fournier A, Fabre A, Mesrine S, Boutron-Ruault MC, Berrino F, ClavelChapelon F: Use of different postmenopausal hormone therapies and risk of histology- and hormone receptor-defined invasive breast cancer J Clin Oncol 2008, 26:1260-1268.

39. Colditz GA, Hankinson SE, Hunter DJ, Willett WC, Manson JE, Stampfer MJ, Hennekens C, Rosner B, Speizer FE: The use of estrogens and progestins and the risk of breast cancer in postmenopausal women. $N$ Engl J Med 1995, 332:1589-1593

40. Bakken K, Fournier A, Lund E, Waaseth M, Dumeaux V, Clavel-Chapelon F, Fabre A, Hémon B, Rinaldi S, Chajes V, Slimani N, Allen NE, Reeves GK, Bingham S, Khaw KT, Olsen A, Tjønneland A, Rodriguez L, Sánchez MJ, Etxezarreta PA, Ardanaz E, Tormo MJ, Peeters PH, van Gils CH, Steffen A, Schulz M, Chang-Claude J, Kaaks R, Tumino R, Gallo V, et al: Menopausal hormone therapy and breast cancer risk: impact of different treatments. The European Prospective Investigation into Cancer and Nutrition. Int J Cancer 2011, 128:144-156.

41. Friedenreich CM: Review of anthropometric factors and breast cancer risk. Eur J Cancer Prev 2001, 10:15-32.

42. Colditz GA, Rosner BA, Chen WY, Holmes MD, Hankinson SE: Risk factors for breast cancer according to estrogen and progesterone receptor status. J Natl Cancer Inst 2004, 96:218-228.
43. Li Cl, Malone KE, Porter PL, Weiss NS, Tang MT, Daling JR: The relationship between alcohol use and risk of breast cancer by histology and hormone receptor status among women 65-79 years of age. Cancer Epidemiol Biomarkers Prev 2003, 12:1061-1066.

44. Clavel-Chapelon F: Cumulative number of menstrual cycles and breast cancer risk: results from the E3N cohort study of French women. Cancer Causes Control 2002, 13:831-838.

45. Russo J, Rivera R, Russo $\mathrm{H}_{\text {: }}$ Influence of age and parity on the development of the human breast. Breast Cancer Res Treat 1992, 23:211-218.

46. Korkola JE, DeVries S, Fridlyand J, Hwang ES, Estep AL, Chen YY, Chew KL, Dairkee SH, Jensen RM, Waldman FM: Differentiation of lobular versus ductal breast carcinomas by expression microarray analysis. Cancer Res 2003, 63:7167-7175.

47. Zhao H, Langerød A, Ji Y, Nowels KW, Nesland JM, Tibshirani R, Bukholm IK, Kåresen R, Botstein D, Børresen-Dale AL, Jeffrey SS: Different gene expression patterns in invasive lobular and ductal carcinomas of the breast. Mol Biol Cell 2004, 15:2523-2536.

doi:10.1186/bcr2790

Cite this article as: Kotsopoulos et al:: Risk factors for ductal and lobular breast cancer: results from the nurses' health study. Breast Cancer Research 2010 12:R106

\section{Submit your next manuscript to BioMed Central and take full advantage of:}

- Convenient online submission

- Thorough peer review

- No space constraints or color figure charges

- Immediate publication on acceptance

- Inclusion in PubMed, CAS, Scopus and Google Scholar

- Research which is freely available for redistribution

Submit your manuscript at www.biomedcentral.com/submit
C) Biomed Central 